\title{
An Exploration into Challenges of Teaching Vocabulary Using Task Based Instruction: The Case of Bodit Secondary and Preparatory School
}

\author{
Tesfaye Buche Bosha, Ayele Eyob Kenta \\ Faculty of Social Science and Humanities, Department of English Language and Literature, Wolayita Sodo University, Sodo, Ethiopia
}

Email address:

tesfayebuche@gmail.com (T. B. Buche), ayeeyob24@gmail.com (A. E. Kenta)

\section{To cite this article:}

Tesfaye Buche Bosha, Ayele Eyob Kenta. An Exploration into Challenges of Teaching Vocabulary Using Task Based Instruction: The Case of Bodit Secondary and Preparatory School. International Journal of European Studies. Vol. 3, No. 1, 2019, pp. 39-45.

doi: 10.11648/j.ijes.20190301.17

Received: March 4, 2019; Accepted: April 4, 2019; Published: May 20, 2019

\begin{abstract}
The main purpose of this study was to explore Challenges of teaching vocabulary using task based instruction at Bodit Secondary and Preparatory School. It is believed that without adequate knowledge of vocabulary, one cannot express him/herself appropriately even if he/she master the grammar of the language and if it is implemented effectively when teaching vocabulary using task based instructions. Communicative language teaching approach was introduced as a main language teaching approach in our country (Ethiopia) two decades ago. However, the vocabulary skill of our high school students is not expected at their level. For example; sometimes students fail to use basic words for communication and even cannot express themselves clearly. The researchers employed descriptive research design in order to gather the needed information to achieve the stated objective and answer the research question. All of eight teachers were selected for this study through convenience sampling technique. To collect valuable and relevant data, interview and classroom observation were used. The semi-structured data transcribed and transformed into textual data form. The observation checklist data were changed to frequency of the numbers. Data was analyzed through cross tabulation and its analysis focused on the thematic expression. The study divulged that majority of English language teachers' they face problem in teaching vocabulary via the task based instruction. The enlisted factors can be grouped into related themes: teacher related, student and facility related factors. Finlay, bearing in mind that divulged in the findings, the respondents listed different factors that affect teaching vocabulary through the task based instruction. Hence, the concerned bodies should fulfill he facility related factors that can affect the teaching of vocabulary via task based instruction, and the student and teacher related factors should mitigate through well-built mobilization.
\end{abstract}

Keywords: Task Based Instructions, CLT, Challenges, Vocabulary

\section{Introduction}

Knowing vocabulary is critical for the comprehension of texts. Building word awareness and vocabulary knowledge requires the students to make a personal construction of meaning and expressions Ahour \& Esfanjani, [2]. In learning and teaching foreign language, vocabulary plays significant roleJežek, [13]. It is one element that links the four major skills of language, i.e., listening, speaking, reading and writing all together. In order to communicate well in a foreign language, students and teachers should acquire and apply an adequate number of words and should know how to use them accurately in communication.
Many scholars, for example, Harmer, [11], Richards, [23], Thornbury, [27], Willkins, [30] noted that without adequate knowledge of vocabulary, we cannot express ourselves appropriately even if we master the grammar of the language. In connection to this, Harmer [11] states" if a language structure makes the skeleton of the language, then It is vocabulary that provides the vital organs and the flesh. An ability to manipulate grammatical structure does not have any potential for expressing meaning unless words are used."

It is obvious that vocabulary is learnt for effective communication "Nation, [22]". A word will die out unless it is used for and in communication. Thus, vocabulary has two dimensions: knowledge and skill of use "Carter, [5]; 
McCarthy, [10]; Nation, [21]; Robinson, [19]."

The command of word knowledge is a prerequisite for using it properly. After 1960, many new ideas and approaches to the study of vocabulary acquisition in a second language given an opportunity to learn how to make choices. This approach gives special attention to the needs and interests of the learners "Richards and Rodgers, [23]; Harmer, [11]."

Accordingly, new English language text books were produced for secondary and preparatory school levels on the basis of the vocabulary teaching through the communicative approach focusing on task based instruction "MOE, [18]." Teaching vocabulary through the task based instruction is better to produce skillful and knowledgeable citizens who can use the target language for various communicative purposes. However, it is not yet differed or researched whether or not vocabulary is taught through the task based instruction. Hence, this study was intended to explore challenges of teaching vocabulary through task based instruction in EFL classrooms in Ethiopian context.

\section{Problem Identified}

Conventionally vocabulary has not been a particular subject for students to learn, but has been taught within lessons of speaking, listening, reading and writing. During the lesson, students use their own vocabulary and are introduced to new words provided by the teacher and classmates which they apply to classroom activities "Xue \& Nation, [30]. In the past, foreign language learners though to vocabulary as learning list of new words with meanings in the native language without any real context of practice. A number of learners may share the same experiences of looking up words in a bilingual dictionary to find their meanings or definitions when they encounter new words "Zimmerman [33]."

According to Wallace [27], the teaching of vocabulary is problematic. The problem arises from these lection of word to be taught. For this reason, before teaching any new words a teacher should make sure what the purpose of the lesson is, whether it fits to students' needs and accomplishes the goal of comprehension and communication. Hassen [12] stated that the commonly observed teacher related difficulties in teaching vocabulary are:

1. Lack of availability of contextual vocabulary

2. Lack of relevant word lists

3. Lack of unique/innovative vocabularylteaching techniques

4. Lack of new ideas

5. Lack of cohesion with the rest of the items taught in the English grammar class

6. Having no sense of direction as to how aspects like spelling and pronunciation of new words can be handled

7. They are not used to adopting any strategies that might help them improve vocabulary retention skill, and even if they do, they are un aware of any such strategies
He also mentioned student related factors that could affect vocabulary teaching, some of them are:

1. Students find English vocabulary difficult even to memorize

2. They feel intimidated by the English language

3. They grow a natural antipathy or in difference towards English words

4. The lesson plan and teaching technique are not conducive to their learning.

The lesson plan of the teachers mainly focus on only the areas of grammar translation and techniques of the teaching is not given much room for vocabulary teaching in an effective and efficient communicative approach. Teachers' strategies of teaching vocabulary are not scientifically acceptable way, which means their teaching strategy is only focused on teaching vocabulary by using bi-lingual word lists and translating English language into mother tongue, and they didn't give much room for communicative activities while teaching vocabulary via CLT. They also negatively perceive the importance of teaching vocabulary for communication and perceive teaching vocabulary via CLT as difficult and challenging issue In their school context. In line with this, Akpınar \& Bardak [3], stated in their findings of the study indicated that presenting collocations with a classification based on the key word, topic-related and grammatical aspects how gains in terms of their retention for all the three levels of the learners who had difficulties particularly in producing them.

In the modern language teaching methods, vocabulary learning includes using words automatically in context appropriate manner. According to applied linguistic point of view "vocabulary is not a goal of itself." We learn vocabulary for effective communication "Nation, [15]." CLT was introduced as a main language teaching approach in our country (Ethiopia) two decades ago. However, the vocabulary skill of our high school students is not expected at their level. For example; sometimes students fail to use basic words for communication and even cannot express themselves clearly.

The above discussion revealed that vocabulary teaching through task based instruction was a challenging and problematic issue in the Ethiopian context. Hence, the mere introduction of CLT as a main teaching approach could not bring the anticipated outcome if it is not effectively used to teach vocabulary. In this regard, this study tried to explore challenges of teaching vocabulary using task based instructions.

\section{Objectives of the Study}

\subsection{General Objective}

The general objective of this study was to explore Challenges of teaching vocabulary using task based instruction at Bodit Secondary and Preparatory School.

\subsection{Specific Objectives}

Specifically, this study was intended to achieve the 
following objective:

To find out the challenges that EFL teachers face while teaching vocabulary via task based instruction.

\section{Research Questions}

This study attempt to answer the following research question:

What are the challenges EFL teachers face while they are teaching vocabulary via task based instruction?

\section{Delimitation of the Study}

The study focused on the challenges of vocabulary teaching through the task based instruction. In addition, the study was limited to find out the possible constraints that teachers face in teaching vocabulary through the task based instruction. To keep the study manageable, the study is delimited only to grade eleven English language teachers of Bodit Secondary and Preparatory School. Accordingly, participants of the study were teachers and their students enrolled in 2009E. C are the setting of the study.

\section{Research Design and Methodology}

This chapter presents methodology of the study specifically; it consists of six sub sections. The first sub section describes there search design. In the second part research setting is briefly discussed. The third sub section deals with the participants of the study. The fourth part describes the sampling technique used to select samples of the study. The fifth sub section presented the instrument of data collection. The last section discussed how data was analyzed.

\subsection{Research Design}

Kothari, [14] defines a research design as "a blue print for conducting a study with maximum control over factors that may interfere with the validity of the findings". Besides, he defines research design as the conceptual structure within which research is conducted.

For this study, the researchers employed descriptive research design in order to gather the needed information to achieve the stated objectives and answer the research questions. The activities to be performed in this study are descriptive in their nature. For this reason, descriptive research design was used to conduct this study.

\subsection{Research Setting}

This study was conducted in Bodit Secondary and Preparatory School which is found in South Nations Nationality Peoples Regional State of Ethiopia Wolaita Zone particularly, in Bodit town. This school is selected due to the following reason. The first reason is for the proximity of the school to the researchers' workplace. The second reason is that there is no any related research conducted in the selected school.

\subsection{Participants of the Study}

As stated above, Bodit Secondary and Preparatory School was selected as a research setting. Thus, the participants of the study were English language teachers. There were eight English language teachers in the selected school. All eight English language teachers were selected for this study; the teachers were practically engaged in the teaching of vocabulary. Thus, it was believed that they could provide the data needed for this study. These eight participant teachers had experience in the teaching of English as a foreign language. Their experience ranged from one up to thirty years of age.

Table 1. Personal Information of the Participants.

\begin{tabular}{llll}
\hline No & Item & Character & Number of Participants \\
\hline \multirow{3}{*}{1} & \multirow{2}{*}{ Sex } & Male & 6 \\
& & Female & 2 \\
& & Total & 8 \\
& & $20-25$ & 1 \\
2 & Age & $26-30$ & 2 \\
& & $31-35$ & 2 \\
& & $36-40$ & 1 \\
& & 41 above & 2 \\
3 & Teaching & $1-10$ & 2 \\
& Experience & $11-20$ & 2 \\
& & $21-30$ & 3 \\
4 & Educational & 31 above & 1 \\
& Background & Degree & 4 \\
\hline
\end{tabular}

\subsection{Sampling Techniques}

The teachers were selected in the convenience sampling technique. According to Dorney [9] convenience sampling is convenient for the researcher to get information. The teachers are implicit to have ample information on practice, perception and strategies of vocabulary teaching via the task based instruction. Thus, all of them were selected for this study through convenience sampling technique. Convenience sampling is particularly purposeful, which means that besides the relative ease of accessibility, participants also have to possess certain key characteristics that are related to the purpose of the study "Dorney, [9]." Therefore, eight of them who were supposed to provide adequate and necessary data for this study were selected using convenience sampling technique to achieve objectives of the study.

\subsection{Data Gathering Instrument}

This research sought to understand the challenges of teaching vocabulary through the task based instruction. To collect valuable and relevant data, interview and classroom observation used to collect data. The interview and classroom observation were developed primarily to meet the objectives of the study; and the items were designed in connection with the literature review, which deals with vocabulary teaching through the task based instruction.

Before gathering data for the main study, the instruments 
were pilot tested in order to ensure their validity and reliability. To apply this, the researchers carried out a pilot study on anon-selected secondary school Damot Gale Woreda particularly in Gacheno secondary school. The data collected during the pilot study were analyzed to see the clarity of the questions and effectiveness of the instruments to collect the desired data. Accordingly, some questions were reported to be unclear and two teachers said they did not understand four of the questions presented to them. Based on the result of pilot data analysis, the instruments were improved, modified and finally used for the main study.

\subsubsection{Semi-Structured Interview}

The researchers set semi-structured interview in English that contained both open-ended and closed-ended items to gather relevant data from teachers about the challenges of vocabulary teaching through the task based instruction.

The interview was developed primarily to meet the objectives of the study and to answer research questions. Besides, the items designed in connection with the literature review, statements of the problem and background of the study which dealt with vocabulary teaching through the task based instruction. The purpose of the interview was to substantiate the results and to obtain a greater depth of information from the participants of the study (respective respondents).

\subsubsection{Classroom Observation}

Among the types of observation, non-participant observation was used to collect data for this study. That was, the researchers a tin the classroom and observed what teachers were actually doing while teaching vocabulary. To gather information in an effective and efficient way, the researchers designed and administered classroom observation.

\section{Methods of Data Analysis}

\subsection{Analysis of Semi-structured Interview Data}

The semi-structured data transcribed and transformed into textual data form. Analysis was done primarily with thematic expressions of the words; using cross check between quantitative and qualitative data. Closed ended questions data were analyzed through using number and open ended question data were analyzed using words and supplement quantitative data. The researchers read the transcribed data considering the objectives of the study. The data that appeared to be relevant to achieve the purpose of this study were selected for analysis. The selected data were categorized according to related themes.

\subsection{Analysis of Classroom Observation}

Eight English language teachers were observed two times while teaching vocabulary via the task based instruction and the observation data was analyzed by counting the responses which was preset observation checklist. The observation checklist data were changed to frequency of the numbers.
Data was analyzed through cross tabulation and its analysis focused on the thematic expression.

\section{Analysis and Discussions of the Results}

The purpose of this study is to explore the challenges of teaching vocabulary through the task based instruction. To achieve this objective, the following question was designed.

What are the challenges that hamper the teaching of vocabulary through the task based instruction?

In order to answer this question and collect the necessary data, semi-structured interview, focus group discussion and classroom observation were used. Besides, eight English language teachers of Bodit secondary and Preparatory school were involved in this study. In this chapter, data collected through close ended question items were presented using number and responses obtained from open ended question items are described and discussed in its thematic relationships and units. Then, the data were presented in line with the objective of the study. The collected data was analyzed through interview and classroom observation was analyzed collectively in order to check cross validation and reliability of data. The analysis and interpretation was focusing each variable or question items independently.

It is assumed that different factors can affect the teaching of vocabulary via task based instruction. In connection to this, an attempt was made to find out the problems that hamper teachers to teach vocabulary through the task based instruction. Furthermore, in the open ended questions English Language teachers were asked to list the challenges that they face while teaching vocabulary via the task based instruction. Accordingly, the teachers mentioned various problems that they face while using task based instruction to teach vocabulary. The English language teachers were asked list out teacher related factors that affects teaching of vocabulary via the CLT approach, particularly, task based instruction. The mentioned common challenges listed by teachers were:

1. Deficiency of vocabulary. The teachers said that they lack adequate vocabulary to teach vocabulary itself. During classroom observation, it was noted that the teachers were teaching English using Amharic or Wolayittatoo language. Thus, it can be said that shortage of vocabulary was common problem for both teachers and students.

2. The teaching methodological problem: The teachers reported that they do not have adequate knowledge how to teach vocabulary via task based instruction. Thus, they are forced to stick to the old language teaching methodology.

3. Lack of awareness about task based instruction to teach vocabulary: The teachers have misconception of communicative language teaching approach particularly task based instruction, perceiving CLT as solely applicable in speaking lesson rather than for vocabulary teaching. As a result, the teachers consider 
task based instruction as a difficult method to use it for vocabulary teaching.

Moreover, English Language teachers were asked to forward student related factors that affect vocabulary teaching via the task based instruction. In response to this, the majority of the teachers pointed out that the commonly student related factors were:

1. Vocabulary itself which means deficiency of vocabulary. It was verified in classroom observation, students were unable to express themselves in target language and they express themselves in vernacular language.

2. Students level of performance and their level of language use. Majorities of students were depends up on teacher teaching instructions and they were waiting such things from the teacher which means dependency was also commonly observed.

3. Lack of attention: The students do not give attention to vocabulary. Rather they give attention to grammar.

4. Negative attitude towards practicing vocabulary skill in communicative exchange.

5. The student lacks basic knowledge of vocabulary aspects like spelling, pronunciation and function of words.

6. Students find English vocabulary difficult even to memorize and anxiety was common problem

7. Shortage of mental dictionaries to produce communication

8. Fearfulness or shyness to speak English

9. Lack of practice to use vocabulary for communication purpose.

Finally, the teachers were asked to mention facility related factor that affect the teaching of vocabulary via the task based instruction. In response, all teachers stated that the commonly facility related factors that affect vocabulary teaching via the task based instruction were:

1. Textbook related factor: The textbook is not suitable for vocabulary teaching via the CLT and there is a lack of adequate teaching textbook (teacher guide).

2. Lack of supplementary materials (reference materials)

3. Shortage of time which means 40'minute is not enough to teach vocabulary via task based instruction specifically to give chance for students in order to practice and using task based instructions in their communicative exchange among one another.

4. The size of the classrooms: The teachers stated that the classroom size is large and it affects the teaching of vocabulary lessons via task based instruction.

\section{Summary, Conclusions and Recommendations}

This study was conducted to divulge the challenges of the teaching vocabulary through the task based instruction focusing on Bodit Secondary and Preparatory School. Specifically, the study was intended to achieve the following specific objective:

To identify the factors that hinder the teaching of vocabulary through the task based instructions.

To achieve the above stated objective, semi structured interviews, and classroom observation were used. The tools were used to collect data from English Language teachers of Bodit Secondary and Preparatory School. The semi structured interview with the English language teachers was used to assess what challenges they faced when teaching vocabulary using task based instruction. Finally, classroom observation was made to validate the response of teachers and to see practical use of task based instruction to teach vocabulary.

The data gathered through the above instruments were analyzed using both quantitative and qualitative methods. The interview data was analyzed using qualitative data to supplement the quantitative data. The classroom observation data were analyzed using frequencies and qualitative description of the responses or events.

Based on the analyses of the collected data, the following summary, conclusions, and recommendations were made. Hence, this part intended to enlist the summary of the major findings, conclusions and recommendations.

\subsection{Summary of the Major Findings}

Different findings were obtained from the analysis of data. The findings of the study were organized and grouped according to the objective of the study. Thus, in this sub section, the summary of the major findings is presented according to the objective of the study.

Factors that hamper the Teaching of Vocabulary via the Task based instruction concerning the factors that hamper the teaching of vocabulary via the TBI, the majority of teachers' face different challenges that affect the teaching of vocabulary via the task based instruction. In relation to this, the majority of English language teacher's forwarded different factors that they face teaching vocabulary via the task based instruction. The enlisted factors can be grouped in to related themes:

1. Teacher related factors that hinder the teaching of vocabulary via the task based instruction were: majority of the teachers have negative attitude towards teaching vocabulary through the task based instruction. This indicates that the majority of the respondents consider that teaching vocabulary through the TBI is not acculturated teaching approach in their teaching experience.

2. Students' related factors that hamper the teaching of vocabulary via the TBI were: lack of students' attention to use TBI in the vocabulary lessons, fearfulness and shyness to speak English, deficiency of vocabulary, unwillingness to learn English language sternly and shortage of mental dictionaries were listed out.

3. Facility related factors that impede the teaching of vocabulary via the task based instruction were: large class size, lack of adequate materials and shortage of 
time allotment.

\subsection{Conclusions}

Owing to the analysis of data and the major findings of the study, the following conclusions were derived.

Teachers are not practicing strategies of teaching vocabulary via the task based instruction which is expected from them. Furthermore, the majority of teachers have deficiency of vocabulary. In this regard, the majority of the teachers do not use the task based instruction to teach vocabulary lessons. The teachers' teaching method dominated in a teacher centered, exam based and grammar translation way.

At the end, it is assumed that different factors can affect the teaching of vocabulary through the task based instruction. Based on the results of the findings the respondents replied different challenges hamper teaching vocabulary via the TBI. These are: teacher, student and facility related factors that can hamper their teaching of vocabulary through the task based instruction.

\subsection{Recommendations}

Based on the findings obtained and conclusion made, the following recommendations are forwarded:

Seeing that divulged in the findings, the respondents listed different factors that affect teaching vocabulary through the task based instruction. Hence, the concerned bodies should fulfill the facility related factors that can affect the teaching of vocabulary via the communicative language teaching approach, specifically task based instruction and the student and teacher related factors should mitigate through well-built mobilization.

Finally, since this area of study is a new phenomenon in the Ethiopian context, the researchers would like to suggest further research to be carried out in different aspects and levels of the same topic at various levels of education.

\section{References}

[1] Anderson, J. 1993. "Is a Communicative Approach Practical for Teaching English in China? Pros and Cons. " System 21/4: 471-480.

[2] Ahour, T., \& Esfanjani, F. J. (2015). Vocabulary learning strategies used by poor Iranian high school students. The Iranian EFL Journal, 11 (1), 224-237.

[3] Akpınar, K. D.,\& Bardakçı, M. (2015). The effect of grouping and presenting collocations on retention. TESL-EJ, 18 (4), 122

[4] Berne, J. and Blachowicz, C. (2008). What reading teachers say about vocabulary.

[5] Carter, R. (1992). Vocabulary, Cloze and Discourse. Harlow: Longman Press.

[6] Carter, R. (1998). Vocabulary: A Linguistic Perspective. New York: Longman Press.
[7] Carter, R. and McCarthy, M. (1988). Vocabulary and Language Teaching. London: Longman Group UK Limited.

[8] Cook, V. 2001. Second Language Learning and Language Teaching. 3rd ed. London: Arnold.

[9] Dorneyi, Z. (2007). Research Methods in Applied Linguistics. Oxford: Oxford U: Press.

[10] Graves, M. F. (1986). Vocabulary Learning and instruction. Washington DC: American Educational Research Association.

[11] Harmer, J. (1991). The practice of English language teaching. New York: Longman Press.

[12] Hassen, N. (2004). Teaching Vocabulary through collaboration. International Journal of Education and Practice, 5 (13) 60-61.

[13] Ježek, E. (2016). The lexicon: An introduction. Oxford, UK: Oxford University Press.

[14] Kothari, C. R. (2004). Research Methodology, Methods and Techniques, Second Revised Edition, New Age International Ltd Publisher, New Delhi Press.

[15] Kumaravadivelu, B. 1993. "Maximizing Learning Potential in the Communicative Classroom." ELT Journal 47/1: 12-18.

[16] McCarthy, M. (1988). Some vocabulary modes in conversation. In R. Carter, \&M. Mc

[17] McCarthy, M. (1990). Vocabulary Teaching Strategies in EFL Context. Oxford: Oxford

[18] MOE (1997)."New English for Ethiopia" Text Books. Addis Ababa, Ethiopia.

[19] Nation, I. S. P. (1990). Teaching and Learning Vocabulary. New York: New bury House Publishers Press.

[20] Nation I. S. P. (2001). Learning Vocabulary in another language. Cambridge, United Kingdom: Cambridge University press.

[21] Nation, I. S. P. (2008). Teaching Vocabulary: Strategies and Techniques. Boston, MA: Heinle Cengage Learning. University Press.

[22] Richards, J. C. (1976). The Role of Vocabulary Teaching. TESOL, Quarterly, 10 (1), 77.

[23] Richards, J. C. \& Rodgers, T. S. (2001). Approaches and Methods in language teaching Second Edition. New York, NY: Cambridge University Press. Instruction Voices from the classroom. Retrieved from Educational full Text data base.

[24] Robinson, P. J. (1989). A rich view of Lexical Competence. ELT Journal, 43 (4), 274-277.

[25] Savignon, Sandra J. (2002). Interpreting communicative language teaching: Contexts and Concerns in Teacher education. United States of American. Yale University Press.

[26] Thornbury, S. (2002). How to Teach Vocabulary. London: Longman Press.

[27] Wallace, M. (1982). Teaching Vocabulary. London: Heine man Educational Books.

[28] Wallace. (2007). Vocabulary: The Key to Teaching English Language Learners to Reading Improvement, 44 (4), 189. 190. 
[29] Willkins, D. A. (1972). Linguistics in Language Teaching. London: Longman Press.

[30] Xue, G. \&Nation, I. S. P. (1984). A University Word List Language Learning and Communication, 3 (2), 215-229.

[31] Zimmerman, C. B. (1997 a). Historical Trends in Second Language Vocabulary Instruction. In J. Coady \&T. Huckin (Eds.). Second Language Vocabulary Acquisition. (PP. 5-9). Cambridge: Cambridge University Press.
[32] Zimmerman, C. B. (1997 b). Do Reading and Interactive Vocabulary Instruction Difference? An Empirical Study TESOL Quarterly, 31 (1), 121-132.

[33] Zimmerman, C. B. (2009). Word Knowledge: A vocabulary Handbook. Oxford: University Press. 